\title{
Artikel
}

\section{Hoe beperkt is het straf(proces)recht voor jongeren met een beperking?}

\author{
R. Kea MSc en Mr. W. van Oppenraaij*
}

In dit artikel vertellen we het verhaal van een jongen met een LVB die in aanraking komt met het jeugdstrafrecht. Wat is er in het straf(proces)recht vastgelegd voor deze doelgroep? Wat is het huidige beleid? Bieden deze kaders voldoende waarborgen om een jongen als Jason de zorg en ondersteuning te bieden waar hij recht op heeft? En zo ja, lukt dit ook in de dagelijkse praktijk? Aan het eind geven we een reflectie op de knelpunten en de verbeterpunten.

Jason is 15 jaar oud als hij in aanraking komt met de politie voor een uit de hand gelopen vechtpartij, waarbij messen zijn gebruikt. Al op de basisschool beginnen de problemen. Op school heeft hij moeite om mee te doen in de klas. Thuis loopt het niet lekker, hij heeft vooral het gevoel te veel te zijn voor zijn ouders. Verschillende hulpverleners hebben geprobeerd om hem te motiveren voor school, maar dit verloopt moeizaam. Op de middelbare school spijbelt hij steeds meer. Met jongens in de buurt hangt hij vaak bij 'het veldje'. Sporten vindt hij heel erg leuk, als hij maar lekker kan bewegen. Hoewel Jason eruitziet net als andere jongens van zijn leeftijd, heeft hij een beperking. Op zijn 14 e pas blijkt uit een psychologisch onderzoek dat er bij Jason sprake is van ADHD en een licht verstandelijke beperking. ${ }^{1}$ Naast een

R. (Ruudje) Kea MSc is criminoloog bij Expect Jeugd, Expertisecentrum Partners voor Jeugd. Mr. W. (Willemijn) van Oppenraaij is jurist bij Expect Jeugd, Expertisecentrum Partners voor Jeugd.

1 R.L. Schalock, R. Luckasson \& M.J. Tassé, Intellectual disability: Definition, diagnosis, classification, and systems of supports, Washington D.C.: American Association on Intellectual and Developmental Disabilities 2021. Volgens de AAIDD wordt gesproken van een (L)VB indien sprake is van: problemen op het gebied van intellectueel functioneren, problemen op het gebied van adaptief functioneren (alledaags aanpassingsvermogen) en een start van de problematiek vroeg in de ontwikkeling van een persoon. In de praktijk wordt veelal gesproken van een LVB als er sprake is lage intelligentie (totaal IQ van 73) is er sprake van tekortkomingen in zijn adaptief functioneren.

\section{Problematiek}

Mensen zoals Jason met een licht verstandelijke beperking (LVB) zijn oververtegenwoordigd in de strafrechtketen. ${ }^{2}$ In de strafrechtketen heeft circa $30 \%$ een $\mathrm{LVB},{ }^{3}$ terwijl dat percentage in de samenleving ongeveer $6 \%$ is. ${ }^{4}$ Een nog zorgelijker beeld zien we in zwaardere daderpopulaties zoals de Top600, ${ }^{5}$ waar bij $56 \%$ van de jongeren sprake blijkt van een LVB. ${ }^{6}$ Mensen met een LVB zijn vaak kwetsbaar, en dat blijven ze hun leven lang, maar zij kunnen met de juiste zorg en ondersteuning gewoon meedoen in onze samenleving. Aan de buitenkant zie je niet dat iemand een LVB heeft, waardoor dit vaak laat of helemaal niet wordt herkend. Het SCP concludeerde in een onderzoek in 2019 dat door de complexer wordende samenleving mensen met een LVB

van beperkt intellectueel functioneren (in de regel een IQ-score tussen de 50 en 85) in combinatie met significante beperkingen in het adaptieve gedrag (conceptuele, sociale en praktische vaardigheden).

2 H. Kaal, 'Het belang van het herkennen van een Ivb in de strafrechtketen', Tijdschrift voor Psychiatrie 2019/6, p. 809-813.

$3 \mathrm{H}$. Kaal, Prevalentie licht verstandelijke beperking in het justitiedomein, Lectoraat LVB \& jeugdcriminaliteit, Hogeschool Leiden 2016

4 SCP, 2019, Het aantal mensen met een licht verstandelijke beperking: een schatting, Notitie ten behoeve van het IBO-LVB.

5 De Top600 is een lijst van 600 personen die de afgelopen jaren relatief veel high-impact delicten hebben gepleegd. Het gaat dan om overvallen, straatroven, woninginbraken, zware mishandeling, openlijke geweldpleging en moord/doodslag. (https://www.amsterdam.nl/wonen-leef omgeving/veiligheid/top600/).

6 M.W. Segeren, Caught in adversity. The development, persistence and escalation of criminal behavior from a public mental health care perspective. Amsterdam: Ipskamp printing 2020. 
steeds meer kampen met problemen op verschillende levensgebieden. Die problemen stapelen zich bij deze groep ook vaker op en kunnen elkaar dan onderling nog verder versterken. Mensen met een LVB kampen vaker met problemen als armoede, een slechte woonomgeving, psychiatrie en hebben vaak weinig prosociale vrienden, factoren die samenhangen met een verhoogd risico op crimineel gedrag. ${ }^{7}$ Als mensen met een LVB en bijkomende problematiek niet op tijd zorg en ondersteuning krijgen, kan dit onder andere leiden tot overlast en criminaliteit. Als strafrechtelijke interventies vervolgens niet worden aangepast op hun niveau, profiteert deze groep niet van het hulpaanbod en wordt er niet effectief gewerkt aan het terugdringen van recidive. Het niet tijdig herkennen en niet juist bejegenen van mensen met een LVB binnen de strafrechtketen kan al eerder in het strafproces leiden tot problemen en rechtsongelijkheid. Kaal (2019) merkt op dat als er tijdens het verhoor geen rekening wordt gehouden met een LVB, men bijvoorbeeld het risico loopt op een valse bekentenis of een schending van de rechten van de verdachte. Als jongeren met een LVB overvraagd worden, kunnen ze uit onmacht bijvoorbeeld agressief gedrag laten zien. Een verkeerde interpretatie van dat gedrag door de politie of andere professionals kan soms leiden tot escalatie. Hierdoor lopen deze jongeren de kans strenger te worden gestraft. Ook blijkt uit onderzoek dat jongeren met een LVB relatief minder vaak geschorst ${ }^{8}$ worden en dus vaker hun straf moeten afwachten in detentie. ${ }^{9}$ Volgens de onderzoekers kan de kleinere kans op een positief schorsingsadvies te maken hebben met niet goed afgestemde communicatie op het niveau van de LVB-jongere.

Passende aandacht binnen het strafrecht en de strafrechtketen voor deze groep zou moeten bijdragen aan meer rechtsgelijkheid, het verminderen van recidive en het bevorderen van participatie in de samenleving. Onderzoekers als Segeren en Kaal pleiten daarnaast voor vroegsignalering van sociaal-emotionele problemen en gezinsproblematiek bij jeugd en passende (langdurige en integrale) nazorg voor delinquenten met een LVB. Onderzoekster Marigo Teeuwen vraagt zich af of een aparte bejegening van mensen met een LVB buiten het strafrecht om niet passender is. Uit haar rapport

7 G. Hindmarsh, G. Llewellyn \& E. Emerson, 'The social-emotional wellbeing of children of mothers with intellectual impairment: A populationbased analysis', Journal of Applied Research in Intellectual Disabilities 2017/30, p. 469-481.

8 De verdachte kan in afwachting van de strafzitting in voorlopige hechtenis worden genomen. Met het stellen van bijzondere voorwaarden, zoals een locatieverbod, een leerproject en begeleiding van de jeugdreclassering kan de voorlopige hechtenis geschorst worden. Binnen het jeugdstrafrecht heeft de rechter-commissaris/Raadkamer de plicht om ambtshalve áltijd te onderzoeken of schorsing mogelijk is.

9 Y.N. van den Brink, H.T. Wermink, K.G.A. Bolscher, C.M.M. van Leeuwen, M.R. Bruning \& T. Liefaard, Voorlopige hechtenis van jongeren in uitvoering. Een exploratief kwantitatief onderzoek naar rechterlijke beslissingen en populatiekenmerken, Den Haag: WODC, Ministerie van Veiligheid en Justitie 2017.
'Levenslange obstakels' ${ }^{10}$ blijkt dat de meeste jongeren tien jaar na begeleiding door de jeugdreclassering nog altijd kampen met multiproblematiek en vaak niet de juiste of voldoende zorg krijgen. Ook ziet zij aanwijzingen voor een mogelijke samenhang tussen contacten met het strafrecht en een toename van multiproblematiek.

\section{Welke waarborgen biedt de wet?}

Een van de beginselen van het VN-verdrag inzake de Rechten van Personen met een Handicap (IVRPH) is dat mensen met een (verstandelijke) beperking volledig en daadwerkelijk moeten kunnen participeren in de samenleving. Zij moeten ten volle al hun rechten en vrijheden kunnen uitoefenen. En op grond van het Internationaal Verdrag inzake de Rechten van het Kind (IVRK) heeft ieder kind met een LVB recht op een volwaardig en behoorlijk leven en recht op bijzondere zorg. ${ }^{11}$ Ook de jeugdige of (jong)volwassene met een LVB die in aanraking komt met het strafrecht en te maken krijgt met verschillende instanties in de strafrechtketen, zoals politie, OM, rechters, (jeugd)reclassering, Raad voor de Kinderbescherming en advocaten, heeft deze rechten. De taken en bevoegdheden van deze instanties liggen vast in onder andere het Wetboek van Strafrecht en het Wetboek van Strafvordering. Ook de positie van de verdachte, diens rechten en diens plichten zijn daarin vastgelegd. In combinatie met de verschillende fasen in het strafrecht ${ }^{12}$ is hier sprake van een ingewikkeld geheel van regels en procedures. Daarin als verdachte met een LVB je rechten kennen en ten volle benutten is niet eenvoudig. De waarborgen voor de verdachte (met een LVB) vloeien voort uit internationale verdragen en nationale wetgeving, en deze bespreken we hieronder.

\subsection{EVRM en IVRK}

Voor Jason en iedere (jeugdige) verdachte geldt het recht op een eerlijk proces uit artikel 6 Europees Verdrag voor de Rechten van de Mens (EVRM). Hieruit vloeit onder andere het recht voort om aanwezig te zijn bij strafrechtzittingen en het recht om de zitting te kunnen volgen. De verdachte moet zich kunnen verdedigen en de verdachte moet kunnen begrijpen wat de inzet van het proces is, welke gevolgen het voor hem kan hebben en wat de inhoud van de verklaringen van getuigen is. Ook het IVRK legt waarborgen vast voor jeugdigen die in aanraking komen met het strafrecht. Zo moet er een

M. Teeuwen, M. Bruggeman, M. Dirkse \& M. Malsch, Levenslange obstakels: Een levensloopstudie naar licht verstandelijk beperkten in het strafrecht en in de zorg, Nederlands Studiecentrum Criminaliteit 2020. https://nscr. nl/app/uploads/2020/06/NSCR_Rapport-Levensloopstudie-LVB.pdf.

11 Art. 23IVRK

12 De fasen in het strafrecht zijn o.a.: de aanhouding door de politie, de inverzekeringstelling, de voorlopige hechtenis en de strafzitting bij de rechter. 
apart jeugdstrafrecht zijn waarin de pedagogische aanpak centraal staat. Vrijheidsbeneming mag enkel als uiterste maatregel worden toegepast en voor de kortst mogelijke passende duur. En juist voor die vrijheidsbeneming moet er alternatieve zorg beschikbaar zijn en moet de herintegratie van de jeugdige worden bevorderd (art. 37 en 40 IVRK). Nederland moet het straf(proces)recht dus zo inrichten dat het voldoet aan de waarborgen uit deze verdragen. Op welke wijze gebeurt dat?

\subsection{Het Nederlandse straf(proces)recht}

Het Nederlandse straf(proces)recht gaat ervan uit dat een persoon in vrijheid zijn wil kan bepalen en zelf verantwoordelijk is voor zijn gedrag. Daarom kan iedereen in beginsel verantwoordelijk gehouden worden voor strafbaar gedrag. Toch houdt het straf(proces)recht rekening met mensen met een LVB, zodat onder andere het recht op een eerlijk proces en een specifieke aanpak voor jeugdigen gewaarborgd kan worden. Dit zien we terug in bepalingen waar gesproken wordt over de kwetsbare verdachte of de verdachte met een verstandelijke handicap en de bepalingen specifiek voor de jeugdige verdachte. ${ }^{13}$

De term kwetsbaar komen we ten eerste tegen in artikel $28 \mathrm{~b}$ Sv. Ter bescherming van de kwetsbare verdachte zegt artikel 28b Sv dat deze verdachte altijd een advocaat krijgt toegewezen voor bijstand voorafgaand aan het inhoudelijk verhoor ${ }^{14}$ en dat hij daar op voorhand geen afstand van kan doen.

Onder de kwetsbare verdachte wordt in ieder geval de verdachte tot 18 jaar verstaan, vanwege zijn of haar jonge leeftijd. Ook vallen alle verdachten en beklaagden hieronder die door geestelijke of lichamelijke toestand of handicap niet in staat zijn een strafprocedure te begrijpen en er effectief aan deel te nemen. Een vermoeden van kwetsbaarheid valt hier ook onder.

Ook in de fase van de strafzitting kan de rechter besluiten om aan de verdachte bij wie sprake is van een vermoeden van een verstandelijke beperking alsnog een advocaat toe te wijzen. ${ }^{15}$

Onder andere hierdoor wordt rechtsbescherming geboden aan verstandelijk beperkte verdachten voor wie de belangen en gevolgen in deze fasen van het strafproces lastiger te overzien zijn.

Voor een verdachte tot 18 jaar gelden nog een aantal extra waarborgen. Diens ouders, voogd of een vertrouwenspersoon mogen bij het verhoor aanwezig zijn (art. 488ab Sv). Dit bestaat naast het recht op bijstand van een advocaat. Het is niet duidelijk of hier in de praktijk veel gebruik van wordt gemaakt. Van de politie wordt niet meer dan een redelijke inspanning gevraagd om de ouders of voogd te informeren.

13 De jeugdige verdachte is de verdachte in de leeftijd tussen 12 en 18 jaar die onder de bepalingen van het jeugdstraf(proces)recht valt.

14 Dit geldt ook voor de verdachte van een misdrijf waarop naar de wettelijke omschrijving een gevangenisstraf van twaalf jaar of meer is gesteld.

15 Zie art. 509a t/m 509d Sv, dit geldt ook voor de verdachte met een psychische stoornis of psychogeriatrische aandoening of een vermoeden daarvan.
Daarnaast is wettelijk vastgelegd dat de jeugdige verdachte medisch onderzocht kan worden om vast te stellen of deze - gelet op diens lichamelijke of geestelijke gesteldheid - in staat is het verhoor of een onderzoekshandeling te ondergaan (art. 489a Sv). Het verhoor kan ook audiovisueel worden opgenomen als de persoonlijkheid van de verdachte ${ }^{16}$ daar aanleiding toe geeft (art. 488ac Sv).

De verdachte jonger dan 18 jaar krijgt vanuit de wet meer bescherming dan de verdachte van 18 jaar en ouder. Echter, in het geval van mensen met een LVB is het juist belangrijk dat zij altijd deze bescherming krijgen, ongeacht hun leeftijd.

\subsection{Het opleggen van een sanctie}

Naast de waarborgen in het strafproces zelf kan bij het opleggen van sancties rekening gehouden worden met een LVB. Voor de jeugdige verdachte kennen we het jeugdstrafrecht met op jeugdigen toegesneden straffen en maatregelen met een meer pedagogische inslag (art. 77a Sr e.v.). Dit is niet specifiek voor jeugdigen met een verstandelijke beperking, maar gaat uit van een oplopende strafrechtelijke verantwoordelijkheid gelet op de nog niet voltooide ontwikkeling van jeugdigen. Onder de 12 jaar is een jeugdige niet strafrechtelijk verantwoordelijk. Vanaf 18 jaar geldt in principe volledige strafrechtelijke verantwoordelijkheid.

Voor jongvolwassenen van 18 tot 23 jaar is wel een uitzondering mogelijk op basis van het adolescentenstrafrecht. In artikel 77c Sr staat dat voor jongvolwassenen, die ten tijde van het begaan van het delict tussen de 18 en 23 jaar oud zijn, op grond van onder meer hun persoonlijkheid een sanctie uit het jeugdstrafrecht toegepast kan worden. Het adolescentenstrafrecht is bedoeld voor kwetsbare jongeren. De gedachte achter het adolescentenstrafrecht is dat sommige jongvolwassenen waarbij sprake is van een nog onvoltooide emotionele, sociale, morele en intellectuele ontwikkeling, beter af zijn met een sanctionering volgens het jeugdstrafrecht. ${ }^{17}$ Uit de praktijk blijkt dat het deel van de doelgroep van het adolescentenstrafrecht waarbij het jeugdstrafrecht daadwerkelijk wordt toegepast zich kenmerkt door het plegen van ernstige delicten, het hebben van een licht verstandelijke beperking (LVB) en multiproblematiek. $^{18}$

Voor de verdachten ouder dan 23 jaar en met een verstandelijke beperking zijn geen specifieke sancties opgenomen in het Wetboek van Strafrecht. ${ }^{19}$ Wel kent het strafrecht ontoerekenbaarheid vanwege een psychi-

16 Het verhoor van de jeugdige verdachte kan ook worden opgenomen als de ernst van het misdrijf daar aanleiding voor geeft.

17 Wijziging van het Wetboek van Strafrecht en het Wetboek van Strafvordering en enige andere wetten in verband met de invoering van een adolescentenstrafrecht, memorie van toelichting, Kamerstukken II 2012/13, 33498, nr. 3.

18 L.J.C. Prop, A.M. van der Laan, C.S. Barendregt, M.G.C.J. Beerthuizen \& Ch. van Nieuwehuizen, Adolescentenstrafrecht. Kenmerken van de doelgroep, de strafzaken en de tenuitvoerlegging, Den Haag: WODC 2018.

19 In opdracht van het ministerie van Jen $\mathrm{V}$ worden wel stappen gezet in visievorming op de sanctietoemeting bij mensen met een LVB, zie in dit 
sche stoornis. In het persoonlijkheidsonderzoek naar de ontoerekenbaarheid wordt gekeken naar de aanwezigheid van een ziekelijke stoornis en/of verstandelijke handicap, vanuit de redenatie dat de verstandelijke handicap invloed kan hebben op de toerekenbaarheid van de strafrechtelijke gedraging. De strafbare gedraging kan dan niet of deels aan de verdachte toegerekend worden. Bij het opleggen van een sanctie kan hiermee rekening worden gehouden door een minder zware straf op te leggen of meer in te zetten op een behandelmaatregel.

Rekening houden met een LVB bij het opleggen van een sanctie kan ook in het kader van een (deels) voorwaardelijke straf. Bij zowel jeugdigen als volwassenen kunnen dan bijzondere voorwaarden opgelegd worden. De bijzondere voorwaarden betreffen bijvoorbeeld behandeling, dagbesteding of opleiding. Ook kunnen voorwaarden betreffende het gedrag opgelegd worden en voor jeugdigen kan dit bestaan uit jeugdhulp. Juist daarbij kan rekening gehouden worden met de verstandelijke beperking en kunnen zorg, training en begeleiding ingezet worden speciaal gericht op de verstandelijke beperking. Bijzondere voorwaarden gaan samen met toezicht en begeleiding van de reclassering. Voor de jongeren met een (licht) (verstandelijke) beperking is er gespecialiseerde jeugdreclassering van de William Schrikker Stichting. ${ }^{20}$

\section{Wat zien we terug in beleid en praktijk?}

Er is dus ruimte in de wet om rekening te houden met jongeren met een LVB, maar wat zien we terug in beleid en praktijk? Een jongen als Jason krijgt in de Nederlandse strafrechtspraktijk te maken met een hele keten aan organisaties zoals het Openbaar Ministerie (OM), HALT, Jeugdreclassering (JR), Reclassering (3RO), Raad voor de Kinderbescherming (RvdK), Politie, ZSM (Zorgvuldig, Snel en op Maat), Slachtofferhulp Nederland (SHN). Gezien de sterke oververtegenwoordiging en de complexiteit van de LVB-doelgroep binnen het strafrecht heeft het ministerie van Justitie en Veiligheid (JenV) de laatste jaren het onderwerp LVB prominent op de beleidsagenda staan. Samen met alle justitiële ketenpartners werd in 2016 de ambitie geformuleerd om voor iedere persoon met een LVB in te zetten op een interventie die aansluit bij de kenmerken en behoefte van de persoon, Tevens werd een verkenning uitgevoerd naar

verband het Verslag experttraject Sanctietoemeting bij LVB van H. Kaal en P. Schuyt, september 2021.

20 William Schrikker Stichting Jeugdbescherming en Jeugdreclassering is een landelijk werkende gecertificeerde instelling die kinderbeschermingsmaatregelen en jeugdreclassering uitvoert en in dat kader hulp en ondersteuning biedt aan kinderen met een (verstandelijke) beperking of chronische ziekte en aan kinderen van ouders met een (verstandelijke) beperking. de knelpunten in de uitvoeringspraktijk, ${ }^{21}$ waaruit bleek dat de praktijk nog onvoldoende was ingericht op deze grote groep kwetsbare personen. Om dit te verbeteren was enerzijds een meer integrale (interdepartementale) aanpak nodig, bijvoorbeeld ten behoeve van de informatie-uitwisseling over (een vermoeden van) LVB of het realiseren van passende (continuïteit van) zorg, huisvesting en dagbesteding. Anderzijds was een extra inspanning binnen de justitiële organisaties zelf nodig, zoals deskundigheidsbevordering gericht op het herkennen van en omgaan met personen met een LVB, werkafspraken over de signalering van de doelgroep en de ontwikkeling van aangepaste interventies.

In 2017 startten vervolgens alle strafrechtelijke ketenpartners om speciale aandacht voor mensen met een LVB in te bedden in de reguliere werkprocessen. Er werden een verbeterplan en een werkagenda opgesteld en recent werd opnieuw een procesevaluatie uitgevoerd naar de stand van zaken. ${ }^{22}$ Daaruit blijkt dat er stappen zijn gemaakt op de werkagenda op het gebied van bewustwording, signalering, communicatie en interveniëren met betrekking tot de LVB-doelgroep. Zo hebben alle organisaties activiteiten, opleidingen en tools ${ }^{23}$ ontwikkeld om bewustwording en herkenning te stimuleren en handelingsperspectieven aan te reiken. Sommige organisaties hebben structureel vakspecialisten of aandachtfunctionarissen op het gebied van LVB aangesteld. Tegelijkertijd blijkt dat professionals nog beperkt gebruik maken van de activiteiten en materialen. Als belangrijkste knelpunt wordt de signalering van een LVB genoemd. Vroegtijdig signaleren van een LVB binnen de strafrechtketen wordt door alle organisaties als randvoorwaarde gezien om vervolgens maatwerk te kunnen bieden. In de praktijk zijn het sociaal verhoor ${ }^{24}$ en de $\mathrm{SCIL}^{25}$ de belangrijkste signaleringsinstrumenten. Vooralsnog wordt de SCIL slechts in een klein deel van de gevallen ingezet. Handelingsverlegenheid, tijdgebrek en de coronapandemie spelen daarbij onder andere een rol. Ook de mogelijkheid om door te vragen in het sociaal verhoor wordt nog weinig benut.

Als een verstandelijk beperkte verdachte voor de rechter moet komen, is het van belang dat hij begrijpt wat er gebeurt en waar het om gaat tijdens een strafzitting. Met andere woorden: dat hij volwaardig kan participe-

21 V. Drost, P. van Haaren \& W. Jongebreur, Mensen met een licht verstandelijke beperking in het justitiële domein Een verkenning naar de huidige uitvoeringspraktijk, Significant 2016.

22 V.Drost, S. Kluft, E. Klein Hofmeijer, E. Reiff \& H. Kaal, LVB in de strafrechtketen, procesevaluatie, WODC 2021.

23 Zoals bijvoorbeeld een basistool voor de strafrechtsketen, justtalk2me. Met deze app kun je pictogrammen op LVB-niveau altijd en overal inzetten om het gesprek met LVB-cliënten visueel te ondersteunen. https:// www.basistoolstrafrechtketen.nl/app-justtalk2me/

24 Politie heeft een 'standaardlijst' met onderwerpen opgesteld om op door te vragen in het sociaal verhoor om een goed beeld van de verdachte te krijgen. Deze informatie kan eenvoudig gedeeld worden in de keten. Hierin wordt ook gevraagd naar mogelijke kenmerken van een LVB.

25 De SCIL is geschikt om snel te screenen op een mogelijke licht verstandelijke beperking. Het gaat om een korte screeningslijst die in negen van de tien gevallen een LVB correct voorspelt. 
ren tijdens een strafzitting, een recht dat voortvloeit uit artikel 6 EVRM en het IVRK. Om dit te realiseren is het van belang dat de andere betrokkenen bij een strafzitting, zoals de rechter en de officier van justitie, weten of signaleren dat de verdachte verstandelijk beperkt is. $\mathrm{Zij}$ kunnen dan in ieder geval in lijn met het VN-verdrag inzake de Rechten van Personen met een Handicap eenvoudige taal en ondersteunende communicatie gebruiken. ${ }^{26}$ Dat dit van belang is, blijkt uit onderzoek naar de jeugdstrafrechtzitting ${ }^{27}$ en onderzoek naar jongeren met een licht verstandelijke beperking in de strafprocedure. ${ }^{28}$ Daaruit leren we dat de verdachten niet altijd goed begrijpen wat er op een zitting gezegd wordt, terwijl zij op de vraag van de rechter of zij het begrepen hebben bevestigend antwoorden. Uit de procesevaluatie van het WODC blijkt dat personen met een LVB overwegend positief zijn over hun ervaring met rechters, maar dat er toch regelmatig dingen onduidelijk of verwarrend waren.

Een ander belangrijk knelpunt in de praktijk is het op tijd vinden en inzetten van passende jeugdhulp. ${ }^{29}$ Zeker sinds de transitie van de jeugdzorg in 2015 is dit voor alle jeugdigen en nog extra voor jeugdigen met een LVB, problematisch.

Ook jongvolwassenen met een LVB die tussen de 18 en 23 jaar oud zijn profiteren door deze problemen mogelijk niet van het adolescentenstrafrecht. Uit een recente evaluatie van het adolescentenstrafrecht blijkt: ' $\mathrm{Er}$ is landelijk variatie in het wel of niet kunnen krijgen van adequate jeugdreclassering of jeugdhulp. (...) Mogelijk worden door knelpunten in de uitvoeringspraktijk en variatie tussen ketenpartners niet altijd de juiste jongvolwassenen geselecteerd die kunnen profiteren van een jeugdsanctie en wordt ook niet altijd de best passende interventie gekozen. ${ }^{30}$

\section{Terug naar Jason}

Toen Jason in aanraking kwam met het strafrecht bleek uit eerder onderzoek al dat er sprake was van een LVB. De officier van justitie en de rechter konden hem hierdoor aanspreken op zijn niveau, waardoor Jason beter begreep wat er gezegd werd en minder boos of opstandig reageerde.

26 In dit verband zijn de 'Guidelines on Childfriendly Justice' uit 2010 van de Raad van Europa van belang die o.a. beschrijven op welke wijze jongeren beter kunnen participeren in juridische procedures, zoals rekening houden met ontwikkelingsniveau, aangepast taalgebruik.

27 S.E. Rap \& I. Weijers, De jeugdstrafzitting: een pedagogisch perspectief. De communicatie tussen jeugdrechter en jeugdige verdachte. Den Haag: Raad voor de Rechtspraak 2011.

28 M. Teeuwen \& M. Malsch, Licht verstandelijk beperkte jongeren in de strafprocedure. Amsterdam: NSCR 2017.

29 https://www.aef.nl/nieuws/onderzoek-structurele-middelen-jeugdhulpgepubliceerd.

30 L.J.C. Prop, M.G.J.C. Beerthuizen \& A.M. van der Laan, Adolescentenstrafrecht. Effecten van de toepassing van het jeugdstrafrecht bij jongvolwassenen op resocialisatie en recidive, WODC 2021, Cahier 2021-05, p. 10.
Uit de procesevaluatie blijkt dat anno 2021 de kans nog steeds groot is dat de politie, reclassering of Raad voor de Kinderbescherming niet signaleert dat er sprake is van een LVB. Deze tijdige signalering is echter noodzakelijk om in alle fasen van het strafrecht te waarborgen dat jongeren en volwassenen met een LVB volwaardig hun rechten kunnen benutten.

Voor iemand met een LVB is het van belang dat hij een sanctie krijgt die past bij zijn leerstijl en mogelijkheden, zodat zo effectief mogelijk gewerkt kan worden aan het voorkomen van recidive en herintegratie in de samenleving. Jason kreeg een gespecialiseerde leerstraf ${ }^{31}$ opgelegd en begeleiding van de gespecialiseerde jeugdreclassering. Hoewel met de bijzondere voorwaarden de mogelijkheid bestaat om op de LVB doelgroep passende hulp of behandeling in te zetten, leert de praktijk dat specifieke (forensische) hulp en behandeling voor deze doelgroep, zeker in het jeugddomein, te weinig beschikbaar is. Dat heeft tot gevolg dat deze jongeren lang moeten wachten op de passende hulp en de jeugdreclasseringswerker in plaats van begeleiding aan de jongere veel tijd moet steken in overleggen met gemeenten, die verantwoordelijk zijn voor de (forensische) jeugdhulp. Ook blijkt uit de evaluatie van het adolescentenstrafrecht dat de problemen met beschikbaarheid en financiering van forensische jeugdhulp het potentiële succes van het adolescentenstrafrecht belemmeren. Jongvolwassenen met een LVB krijgen hierdoor niet de hulp die past bij hun nog onvoltooide ontwikkeling.

Aan strafrechtelijke sancties zit altijd een termijn. Zo was ook de gespecialiseerde jeugdreclasseringsbegeleiding van Jason eindig. Na een intensieve begeleidingsperiode en in samenwerking met een stichting die wel raad weet met jongens als Jason durfde hij weer te dromen over wat hij zou willen met zijn leven en nam hij zelfs het initiatief om een opleiding te gaan volgen als dierenverzorger. De begeleiding zou zijn opgehouden als de jeugdreclasseringswerker niet samen met een gemeente gezocht had naar mogelijkheden om hem nog langer te laten begeleiden.

Mensen met een LVB hebben recht op een eerlijk proces, een eerlijke straf en de best passende hulp. Vanuit het (verdrags)recht zijn er in beperkte mate waarborgen voor LVB'ers in het straf(proces)recht. We denken dat een aanpak buiten het strafrecht om niet altijd nodig is. Ook mensen met een LVB kunnen met de juiste uitleg snappen wat wel en niet mag, herstellen wat is misgegaan en leren van hun fouten. Dan moeten zij wel de hierboven genoemde rechten kunnen benutten. Daarvoor is tijdige signalering van de LVB en kennis en kunde rondom deze doelgroep in de strafrechtketen onontbeerlijk.

Hoewel hier stevig op wordt ingezet, blijkt dit anno 2021 nog niet voldoende van de grond te komen. De jeugdstrafrechtketen is een klein puzzelstukje van een groter

31 So-Cool is een erkende leerstraf waarbij jongeren met een LVB cognitieve en sociale vaardigheden leren. 
zorgsysteem dat te ingewikkeld is georganiseerd. ${ }^{32}$ Het realiseren van de benodigde levenslange continuïteit van zorg voor deze groep is erg ingewikkeld door de verschillen in wet- en regelgeving met betrekking tot zorg voor jongeren en zorg voor volwassenen.

We zien dat in de hele strafrechtketen hard wordt gewerkt om structureel meer aandacht te hebben voor LVB-problematiek, maar passende bejegening en begeleiding lijkt nog te veel afhankelijk van individuen binnen de strafrechtketen of bepaalde beroepsgroepen. Een sterkere verankering van onder andere structurele signalering en aangepaste bejegening in wetgeving, beleid en praktijk is nodig, zodat de levenslange ondersteuningsbehoefte van mensen met een LVB echt leidend wordt in de zorg en begeleiding van deze groep. 